\title{
Noise Equivalent Count Rate
}

National Cancer Institute

\section{Source}

National Cancer Institute. Noise Equivalent Count Rate. NCI Thesaurus. Code C94941.

An adjusted PET scanner's count rate that results from a specified activity concentration within. 